\title{
WHOSE GAY COMMUNITY? SOCIAL CLASS, SEXUAL SELF-EXPRESSION, AND GAY COMMUNITY INVOLVEMENT
}

\author{
Donald C. Barrett* \\ California State University, San Marcos \\ Lance M. Pollack \\ University of California, San Francisco
}

\begin{abstract}
The visible and political gay community has been characterized as an increasingly middle-class, white institution. It is hypothesized that this middle-class nature requires economic and psychosocial resources that are not available to the working class and, thus, may limit the expression of sexual orientation for the working class. An analysis of data from the multicity Urban Men's Health Study supports this hypothesis. Nine of 14 hypothesized effects are statistically significant and indicate that working-class men who are homosexually active are less likely to describe themselves as gay, are more likely to have heterosexual experience, and are less likely to be involved in the gay community. Thus, it is important to incorporate class differences when addressing the social and the political dynamics of sexual orientation.
\end{abstract}

\section{INTRODUCTION}

As has been noted by a number of researchers on gay ${ }^{1}$ culture and gay political activities, the image of gays presented by the contemporary popular press and by gay political organizations is an increasingly middle-class image (see Shugart 2003). Gay males and, to a lesser extent, lesbians, are depicted as having the affluence to be relatively high consumers of goods, with professional or white-collar occupations, frequently in stable dyadic romantic relationships, often with children, and rightfully due the legal benefits of other nongay, middle-class Americans. As Valocchi and others argue (see Valocchi 1999), this middle-class representation of gays is partly due to the historic, economic, and social forces that facilitated the development of a middle-class gay movement and partly due to the contemporary gay lifestyle choices that require the residency, employment, and consumption patterns of the middle class. Most importantly, as both Shugart and Valocchi suggest, this middle-class trait of gay life is likely to be an artifact of those who are homosexually active and who are open or are known by others to be homosexually active. That is, the images and culture are reflective of those who have the resources to be open about

${ }^{*}$ Direct all correspondence to Donald C. Barrett, Sociology Department, California State University, San Marcos, CA 92096-0001; e-mail: dbarrett@csusm.edu 
their sexual orientation and are not necessarily reflective of all who are homosexually active.

While issues of sexual self-expression and community involvement for minorities have previously been raised, research investigating a specific class bias has been limited (Barrett 2000). An assumption of a class bias raises the question of how the ability (or the desire) of individuals to express their sexual orientation would be shaped by the resources associated with social class. It is proposed here that variance in social class results in differential access to the social, psychological, and economic resources that facilitate the ability to express one's sexual orientation.

The following three sections provide a framework for understanding the relationship between social class and the expression of sexual orientation. The first section focuses on the likely effects that are specifically due to social class; the second section focuses on those effects that are likely to be due to the intersection of social class and masculinity standards. The third section then converts these possible effects into specific sexual expression and community involvement outcomes that can be assessed with the available data. It is important to stress that the available data allow only for the examination of the expected outcomes of the proposed social class and masculinity effects. The analysis, thus, suggests possible validity for the social class and masculinity processes described below but does not allow for the testing of those specific processes. This limitation is further addressed in the discussion.

\section{Social Class Effects}

One likely cause for a relationship between social class and expression of sexual orientation is differential access to economic resources. The historic lack of acceptance of gay life-styles by the broader culture creates a situation where many find it necessary to find an environment where one can meet others and can feel relatively safe in expressing one's sexuality. ${ }^{2}$ Thus, we have a modern history of many men, who identify themselves as gay, gravitating toward occupations and/or cities and locales (e.g." "gay ghettos") that provide more freedom to "be gay." Such migration requires resources that may not be available to working-class gay men (Escoffier 1998).

Although there appears to be an increasing acceptance of gays in general across the country, the levels of acceptance of gays are consistently higher in urban and suburban areas and among those with higher education or income (Bowman 2004). While circumstantial evidence suggests that living within the safety of the traditional and the relatively closed "gay ghetto" may be of decreasing importance, the demographic of acceptance suggests that major urban centers (i.e., metropolitan areas with a million or more inhabitants) and unique resort communities (e.g., Provincetown, Palm Springs) continue to provide an environment that is more accepting of diversity and, thus, is preferred by many who identify themselves as gay or lesbian. Typically, the cost of living in such areas is high, thus, creating a class bias that is related to geographical residency. This cost-of-living effect can be manifested in either or both of two ways: 1) ability to migrate to such urban areas and 2) ability to afford housing that allows flexibility with regard to sexual expression (e.g., living alone or with a sexual/emotional partner) when living in such areas. 
A second economic relationship that is likely to be related to social class is the nature of work. Working environments would be expected to differ in the level of acceptance of gays by others in the workplace, with the lower acceptance of gays by those with lower education or income, creating uncomfortable or even hostile work environments for working-class gay men. Considering the amount of time spent in the workplace and the amount of nonwork social life that is frequently related to work, working in a nonaccepting environment is likely to have a suppressive effect on one's ability to express one's sexual orientation.

A third and somewhat less obvious economic relationship is what might be termed the "lifestyle" costs of gay expression. It has been suggested that the visible gay culture is unusually consumerist, a situation that is possibly due to the fact that establishing a subculture is facilitated by adopting tangible signs and actions that enhance recognition as gay (Valocchi 1999). Since creating a subculture requires both cultural signs and action, there are likely to be both monetary and occupational costs associated with participating in the visible gay culture. Clearly staying abreast of current trends in fashion, electronics, furnishing, transportation, entertainment, recreation, and travel have real monetary costs. Not quite as clearly, participating in gay-related activities and events is also facilitated by the sorts of relatively flexible work schedules associated with professional and white-collar occupations and is hampered by the more rigid work schedules found in working-class jobs where evening or weekend work may be required and time off may require more preplanning.

Clearly, some working-class gay men have well-paying jobs and can afford to live in modern urban gay centers and, clearly, some men from working-class backgrounds have achieved middle class occupations in industries that are tolerant or even welcoming of gays (e.g., academic positions). But, both class and sexual orientation are about much more than income and access to sexual partners. Thus, if the available gay culture is middle class, feeling a sense of fit may be unlikely even for those who have attained some of the more superficial trappings of middle class.

One of the ways in which class is likely to affect one's sense of fit with a middleclass gay culture is in how gay men develop relationships and friendships for meeting emotional, sexual, and social needs. Patterns of behavior involving divorce and separation, marital instability, or episodes of violence (physical or verbal) in those relationships are all more likely in working-class backgrounds (White and Rogers 2000; South 2001; Cunradi, Caetano, and Schafer 2002). Given this background, we would expect working-class gay men to be more likely to have problems forming the sorts of long-term intimate relationships that are more common among middle-class gays (Conger, Cui, Bryant, and Elder 2000). A second effect of social class is the likelihood of having the sense of commonality and shared experiences in work, travel, recreation, entertainment, or related interests that would facilitate the formation of friendships with middle-class gays (Connell 1992). Finally, and closely related to the previous, is the effect of social class on styles of social interaction. Assertiveness or passivity in conversation, comfort in talking with others, and posture and demeanor in general are all related to social class and would affect the likelihood of forming 
bonds in social groups where middle-class interaction styles are the norm (Lareau 2002).

Thus, based on both relatively tangible economic factors and less tangible psychosocial resources, we would expect working-class gay men to have different experiences in identifying as gay and in utilizing the resources of the gay community.

\section{The Interaction of Class and Masculinity}

Besides the effects on participation in the gay culture that are specifically related to the opportunity structure and social dynamics of class, it is essential to also bring into consideration the class dynamics regarding the expression of masculinity. As has been noted elsewhere (Connell, Davis, and Dowsett 1993; Barrett 2000), assumptions about the appropriate expression of masculinity are closely linked to social class. In general, there is a cultural assumption that masculinity among working-class men is characterized as being less refined and more physical, expressed through relatively unsophisticated language and behaviors that are replete with demonstrations (verbal or physical) of strength, heterosexual prowess, and impatience with weakness. This working-class conception of masculinity is very distinct from the one promulgated in the middle class that is characterized as being more nuanced in its expression of strength and prowess, where demonstrations of a relatively emotional empathy are expected, and where language and behavior are expected to be more refined and negotiable in tone.

While many academics have correctly questioned whether such stark class contrasts in expectations about masculine expression are consistently maintained in society (Connell 1995; Ehrenreich 1995), it is clear that support for this physical masculinity remains relatively strong and may, in fact, have increased in the early stages of the 21st century as evidenced in the media attention to the "NASCAR (National Association for Stock Car Auto Racing) dad" phenomenon (Chinni 2004; M. C. 2004). If an emphasis on this more physical (and heterosexist) masculinity for the working class remains (or is increasing), then there are likely to be two different masculinity-related problems with expressing one's sexual orientation. One problem would be that the work and workrelated social conditions of working-class men are less likely to be accepting of gays, thus creating a need to hide an important part of one's life during the large portion of the workday for those that are gay. Additionally, the class-influenced differences in expectations of the expression of masculinity may create a problem in how well working-class men can interact with the more middle-class gay community.

It is important to note, however, a possible contradiction to this masculinity hypothesis. Images of a blue-collar expression of masculinity have a relatively long history of use in the gay community (Levine 1998). The most famous example of using working-class imagery was in the popularity of the musical group The Village People within gay culture. Its cast of blue-collar masculinity (cowboy, construction worker, cop, soldier, biker, and American Indian) would strongly suggest a resonance within gay culture for workingclass masculinity. Evidence of an appreciation of working-class masculinity is also indicated in the popularity of "bear" and leather subcultures within gay culture. Despite the popularity of working-class (particularly blue-collar) imagery in gay culture, it is 
important to note that this imagery may be more about presentation as ruggedly, downto-earth masculine than about the actual presence or acceptance of working-class men within the culture. The fact that the image is frequently used in advertisements for businesses, services, and travel where purchases require a fair amount of disposable income reinforces the likelihood that the imagery is used for middle-class fantasy purposes and not to appeal to actual working-class or blue-collar gays.

\section{Social Class, Sexual Self-Expression, and Community Involvement}

Given the possible processes of social class and class-defined masculinity mitigating the expression of sexual orientation, what specifically might we expect as the effects of social class on sexual self-expression and community utilization?

Considering the economic, social interaction, and masculinity linkages described earlier, we would expect that working-class men with same-sex emotional and sexual needs would lack the economic and social resources that facilitate the various social interactions that are helpful in resolving sexual orientation issues and would be less inclined to label themselves as gay because of standards of masculinity. Thus, we would expect working-class men to be less likely to readily label themselves as gay and, for those who do, we would expect to find a longer time lag between initiation of same-sex sexual activity and such self-labeling. ${ }^{3}$ Thus, this study examines the effects of social class on two measures of self-labeling: whether the subject describes himself as gay and the time lag between age of first initiation and the age at which he first tells someone that he is gay.

Turning to community involvement, it is likely that social class will influence economic, social-psychological, and masculinity factors that in turn will impact community involvement. As noted previously, we would expect that working-class gay men are less likely to be able to afford to live in areas where political and social activities are readily available and may also be less likely to have the work flexibility to participate in such activities. The class differences in interaction styles, commonality of interests, and attitudes toward masculinity may also make it less comfortable or desirable to live in middle-class gay areas or to participate in relatively formal social and political activities that require interaction with others. In addition, if the hypothesis of later self-labeling is true, then working-class gay men would be expected to have less experience with using those gay community social resources and, thus, would be less likely to use them. This study examines the relationship between social class and these two broad factors: residency and participation in relatively formal social and political activities.

Clearly intertwined with class, gender, sexual self-expression, and community involvement are the acts of meeting and fulfilling personal emotional and sexual needs. For all men who are sexually active with men, finding and developing both intimate relationships and close friendships are likely to be hampered by the fact that the development and the maintenance of such relationships are not legitimated in the broader culture. Thus, efforts to meet such needs would be facilitated by interacting with likeminded others within the gay subculture. However, if the earlier hypotheses about relationships between working-class gays and the larger gay community are true, then the differences in identification with other gays and the utilization of the gay community are 
also likely to inhibit the ability of working-class gays to develop same-gender intimate relationships.

In addition to the effects related to interaction with the gay community as described above, two more class-specific factors should also affect the nature of social relationships. First, since the development of relationships is influenced by the models for relationships encountered early in life, and the working class is less likely to come from a history of stable relationships, we would expect working-class men to be less likely to be in long-term relationships. Second, considering the emphasis in working-class masculinity on heterosexual prowess, we would expect working-class men to be more likely to have been involved in sexual relationships with women.

To examine the effects of social class and gender on meeting emotional and sexual needs, this research addresses the relationship between social class and a number of different factors. As suggested by the above, one factor will be a history of heterosexual relationships, and another will be the existence of at least one primary partner relationship. Since not all emotional needs are necessarily sexual, we will also examine the utilization of less formal community resources (e.g., bars and public cruising areas) that may serve as venues for meeting socially with other gays and/or for meeting sexual partners.

\section{METHODS}

The data for these analyses are from the Urban Men's Health Study (UMHS), a telephone interview completed between November 1996 and February 1998 of a probability sample of men who have sex with men (MSM) living in Chicago, Los Angeles, New York, and San Francisco. The collection of the UMHS data and the sample's representatives of MSMs have been addressed extensively in other articles utilizing the data set (see Catania et al. 2001 or Barrett, Pollack, and Tilden 2002). The sample consists of 2,881 men aged 18 and older who reported having same-gender sex since age 14 or who identified themselves as gay or bisexual. Since the focus of this study is on examining the effects of social class on the expression of sexual orientation and on the involvement with the gay community, the selected sample should reflect those men who would be likely to engage in such behaviors if social class was not a factor. To remove those men who were included in the original sample based on early experimentation but to keep those likely to interact with other homosexually active men or with the gay community, this subsample includes those men who reported being sexually active with men in the last five years $(\mathrm{N}=2,580)$ and those who were sexually active only with women in the last five years but described themselves as bisexual or homosexual $(\mathrm{N}=25)$. The resulting analytic subsample consists of 2,605 men.

The focus of UMHS was human immunodeficiency virus (HIV), so the interviews covered social, psychological, and health topics with an emphasis on HIV issues. Fortunately, the breadth of the measures included in the UMHS interview allowed for a close examination of the effects of social class on sexual self-expression and on community involvement. 


\section{Independent Variables}

\section{Social Class and Related Control Variables}

Ideally, social class is measured with a combination of variables that incorporate work characteristics along with income, assets, education, and family background factors. Education and income, however, are reasonably good surrogate measures of social class (Winkleby, Fortmann, and Barrett 1990; Adler et al. 1994) and, thus, we used measures of the respondent's education and income in this analysis.

The education of the respondent was measured on a 9-point scale ranging from never attended school to doctoral degree. An examination of the logistic regression analysis indicated that the effects of education on the outcomes was linear; thus, years of education is used with education recoded into years of schooling ranging from 3 to 20 .

The respondent's income was measured as household income. Although household income is not an exact indicator of the subject's earnings, it is an indicator of household resources and is thus treated as an indicator of social class for this analysis. Household income was asked with ordered categories, in which the first two categories used a range of $\$ 10 \mathrm{~K}$ (less than $\$ 10,000$, between $\$ 10,001$ and $\$ 20,000$ ); the next four categories used a range of $\$ 20 \mathrm{~K}$ (e.g., between $\$ 20,001$ and $\$ 40,000$ ), with the top category being “over $\$ 100,000$." For analysis, the first two categories were combined so that all categories (except the top) assessed $\$ 20,000$ increments. An examination of the logistic regression analyses indicated that the effects of income on the outcomes were not consistently linear; thus, income was treated as a categorical variable in this analysis.

With the focus of this analysis being on social class, it was important to statistically adjust for two other factors that may confound any social class effects. Since the social class effects for racial and ethnic minorities were likely to be compounded by effects because of cultural differences and discrimination, a measure of being nonminority was included in all analyses. Respondents who described themselves as white were coded 1; all other racial groups were coded 0 . The second factor to adjust for is age. With respondents as young as 18, adjusting for age helps to ameliorate any effects that may simply be due to being too young to have advanced educationally or to have the workforce experience that enhances income. In keeping with previous analyses using the UMHS data set, age was recoded into decades in the regression analyses. Preliminary analyses indicated that the relationship between age and the outcomes was not consistently linear; thus, age was treated as a categorical variable.

\section{Dependent Variables}

Fourteen variables were used to assess the relationship between social class and the outcomes assessing the expression of sexual orientation and gay community involvement. Many of the measures assessing the outcomes were continuous variables, and the majority of these continuous variables had nonnormal distributions that violated the assumptions of linear regression. So that logistic regression can be used in all analyses, all continuous variables were dichotomized using either a theoretical or a statistically defined split. 


\section{Sexual Self-Expression and Sexuality Outcomes}

Three measures were used to assess whether social class is related to the expression of one's sexual orientation. The first measure, of whether the respondents label themselves as gay, was used to assess whether the respondents use either of the socially prescribed labels ("gay" or "queer") to describe themselves. The use of either of these labels was assumed to suggest some sense of affiliation with gay culture. The respondents were asked whether they thought of themselves as gay, queer, bisexual, homosexual, heterosexual, straight, or as something else. The respondents who used the terms "gay" or "queer" in describing themselves were assigned a value of 1 for self-labeling as gay; all other respondents were assigned a value of 0 .

The second measure assessing the relationship between social class and sexual self-expression was a measure of the difference in years between when a respondent first became sexually active with males and when they first told someone else that they were gay. ${ }^{4}$ As is common with questions asking for the ages of various stages of sexual development, the majority of respondents gave answers that fit within what would be expected, but a significant minority did give nonconforming answers. Although the majority of men reported their first male-male sexual activity as occurring at a time consistent with the onset of puberty (90 percent reported their first experience as occurring at age 9 or older), 4 percent reported that their first malemale sexual activity occurred at age 6 or younger. Similarly, it might be expected that most men would tell someone that they are gay at some time close to the time of their first sexual experiences with other males, but 6.7 percent reported telling someone that they were gay two or more years before their first experience, and 3.1 percent never told anyone that they were gay. ${ }^{5}$ These variations resulted in a difference score that is not normally distributed (range: -17 to 61 ; mean: 5.15 ; median: 3.00 ; standard deviation [SD]: 8.08); thus, the sample was divided into those who disclosed at or below the median of three years after first experience and those who disclosed later.

A third measure assessed the degree to which the respondent is open to others about being gay. The respondents were asked the extent that they were out to family, friends, neighbors, coworkers, and employers. The response set was out to "no one," "less than half," "about half," "almost all," or "all." A general openness scale was derived by combining all five variables (alpha $=.84)$. Since each of the five variables measuring outness allowed the respondents to answer "not applicable" if they were not in the situation, values for this scale were calculated only if the respondents answered at least three of the five questions. The scale scores were the average of the questions answered, and the scale was skewed toward openness (range: 1 to 5; mean: 3.90; median: 4.25; SD: 1.13). Considering the hypothesis that class is linked to being open about being gay, the scale was dichotomized into average scores greater than 3 (out to about half) or less than 3.

It was also hypothesized that lower social class would be related to sexual experience with women; thus, a fourth measure was included, which was whether or not the respondent reported being sexually active with women within the past five years. ${ }^{6}$ 


\section{Gay Culture Measures}

Multiple measures were used to assess whether social class is related to interaction with gay culture and feelings about gay culture. One indication of participation in gay culture is involvement in gay social groups. The respondents were asked if they had participated or attended the meetings of seven different types of organizations ${ }^{7}$ in the last year and whether the membership of those organizations was heavily attended by gay or bisexual men or by lesbians. A count of the number of different types of heavily gay/lesbian organizations attended was skewed toward a low number of organizations (range: 0 to 7; mean: 1.69; median: 1; SD: 1.48). Considering the hypothesis that class is linked to participation in organizations through both economic resources and identification as gay, the scale was dichotomized into none versus any participation in gay organizations.

Another indication of participation in gay culture would be readership of the gay press. The respondents were asked how often they read national gay papers in the previous three months, with responses of "never" (1), "once" (2), "twice" (3), "three or more times" (3). The responses to the variable were not normally distributed with the majority (51.7 percent) answering "never" and the next most frequent answered category being "three or more times" (28.2 percent). Since most national gay publications require subscription or purchase at a gay or gay-friendly business, a reasonable test of interest and involvement in gay issues would be any readership, and thus, the variable was dichotomized into none versus any readership.

The respondents were also asked their level of agreement with a series of statements that assess attitudes toward the gay community. The responses to the statements factoranalyzed into two scales. One of the scales measured the perceived exclusivity of the gay community (alpha $=.58$ ) with three items asking about the effects of age, appearance, and race on community acceptance. The second scale measured the overall affiliation with the local gay community (alpha $=.78$ ) with seven items asking about whether the respondent feels that he is a part of the community, feels that participating in the community is a positive thing to do, feels a bond with other men who are gay, feels proud about the community, feels it is important to be politically active in the community, whether working with others can solve community problems, and whether the respondent feels that problems in the community are his problems as well. The response set for all 10 items is "agree strongly," "agree somewhat," "disagree somewhat," and "disagree strongly" and was scored so that a higher score indicates stronger feelings. The scale scores are the average of the item scores and were calculated only for respondents who answered at least two thirds of the items used in the scale. The affiliation score was skewed toward high affiliation (range: 1 to 4; mean: 3.31; median: 3.43; SD: .53). For this analysis, the scale was dichotomized at the equivalent of an overall level of feeling disagreement regarding affiliation (lower than 3.0). The exclusivity score was more normally distributed (range: 1 to 4 ; mean: 2.61 ; median: 2.67 ; SD: .77) and is dichotomized for this analysis at the equivalent of agreement (3.0 or higher) that the gay community is exclusionary. ${ }^{8}$

Based on the sampling frame for the study, it was also possible to assess whether the respondents lived in a neighborhood that was popularly considered to be a gay 
neighborhood. The respondents were considered to be living in a gay neighborhood (also frequently referred to as "gay ghetto") if they lived in the two zip codes in that city with the highest concentration of MSM (see Mills et al.2001). Because of variations in the density of gay neighborhoods by sample city, multivariate analysis for this variable adjusts for city.

\section{Gay Intimacy and Socializing}

Whether the respondents have partners and how they socialize with other gay men is also an indicator of the extent of their involvement with gay culture. Five measures were available to assess this. The first was whether the respondent states that he is in a relationship with another man whom he would describe as his domestic partner.

The respondents were also asked how many times in the past 12 months they had used each of four types of venues to meet or to socialize with other men: (1) a bar, night club, or dance club; (2) private parties; (3) a sex club or bathhouse; and (4) a public cruising area, such as a park, beach, t-room, or bookstore. The responses for each of the measures were skewed toward low use. Two measures, attending bars/night clubs (range: 0 to 999; mean: 35.10; median: 15.00; SD: 56.56) and private parties (range: 0 to 400; mean: 13.04; median: 8.00; SD: 19.83) were dichotomized at the median. For the other two measures, attending sex clubs (range: 0 to 200; mean: 3.31; median: 0.00; SD: 11.16) and public cruising areas (range: 0 to 5.00; mean: 6.52; median: 0.00; SD: 26.56), the majority of subjects did not attend and so were dichotomized into none versus any attendance.

\section{Data Analysis}

Multiple logistic regressions were performed to examine whether the relationships between the dependent variables and the independent variables were linear or not. The results of these runs were noted earlier in the description of the independent variables. All regressions, including the final runs, examined the Hosmer-Lemeshow goodness-of-fit test, and where the fit score was less than .20 , modifications to the equation were made. Since the focus of the analyses is on relationships among variables rather than on generalization of point estimates, unweighted data were reported.

\section{RESULTS}

Table 1 describes the subjects used in this analysis. As the demographics suggest, the sample is relatively well educated (average education is just under a Bachelor of Arts [BA] [16 years]) and with a fairly high household income (58.5 percent have household incomes of more than $\$ 40 \mathrm{~K})$.

Tables 2 through 7 illustrate the statistical relationship between measures of social class and the various outcome measures. The following sections discuss these results in terms of the hypothesized effects; the results for the covariates (age and minority status) are not discussed. 
TABLE 1. Sample Characteristics $(\mathrm{N}=2,605)$

\begin{tabular}{ll}
\hline Variable & Percent or Mean (Standard Deviation) \\
\hline Demographics & \\
Education (3-20) & $15.95(2.14)$ \\
Income & 14.5 \\
$\quad<20,000$ & 27.0 \\
$\quad \$ 20,001-40,000$ & 21.0 \\
$\quad$ 40,001-60,000 & 13.7 \\
$\quad$ \$60,001-80,000 & 7.7 \\
$\quad$ 80,001-100,000 & 16.2 \\
$\quad$ \$100,000 & $38.95(10.87)$ \\
Age (18-85) & 79.1 \\
Nonminority & \\
Self-labeling and sexuality & 77.0 \\
Self-label as gay & 47.2 \\
Three-year disclosure gap & 79.1 \\
Openness (out to half or more) & 15.0 \\
Bisexual in last five years & \\
Gay community & 48.3 \\
Readership national gay press (at all) & 74.6 \\
Attend any gay groups & 39.2 \\
Community exclusivity (agree) & 20.4 \\
Community affiliation (disagree) & 43.8 \\
Live in gay ghetto & 31.3 \\
In primary relationship with male & \\
Times socializing in last 12 months at: & 50.7 \\
Bars (greater than median of 14 times) & 51.1 \\
Private parties (greater than median of 9 times) & 30.7 \\
Sex clubs (any use) & 38.4 \\
Public cruising areas (any use) & \\
\hline
\end{tabular}

\section{Sexual Self-Expression and Sexuality}

As shown in Tables 2 and 3, social class is related to three of the sexual self-expression and sexuality measures in the direction expected. After adjusting for age and race, both higher education and higher income are related to increased odds of labeling oneself as gay. The effect of income on labeling oneself as gay is somewhat curvilinear with the odds ratios increasing in size as income increases but decreasing at the highest category.

The respondents' class background was also related to the amount of time between when they first became homosexually active and when they first told someone that they were gay, with higher education being related to reduced odds of there being a long gap (three or more years) between these events.

Since the measure of sexual experience with women is based on behavior in the past five years, and such experience typically occurs in the young adult years in this sample (32 
TABLE 2. Logistic Regression Analysis of Self-Labeling and Sexuality

\begin{tabular}{|c|c|c|c|c|}
\hline & \multicolumn{2}{|c|}{ Self-Label as Gay } & \multicolumn{2}{|c|}{ Three-Year Disclosure Gap } \\
\hline & & (95 percent & & (95 percent \\
\hline & Odds Ratio & Confidence Interval) & Odds Ratio & Confidence Interval) \\
\hline Education (years) & $1.06^{*}$ & $(1.01-1.11)$ & $0.95^{\star}$ & $(0.92-0.99)$ \\
\hline \multicolumn{5}{|c|}{ Income (compared to $<\$ 20 \mathrm{~K}$ ) } \\
\hline$\$ 20,001-40,000$ & $1.40^{\star}$ & $(1.05-1.87)$ & 1.07 & $(0.82-1.41)$ \\
\hline$\$ 40,001-60,000$ & $1.85^{\star * \star}$ & $(1.34-2.54)$ & 1.10 & $(0.82-1.47)$ \\
\hline$\$ 60,001-80,000$ & $2.20^{* * *}$ & $(1.51-3.20)$ & 1.20 & $(0.87-1.65)$ \\
\hline$\$ 80,001-100,000$ & $2.29^{\star * *}$ & $(1.43-3.66)$ & 0.97 & $(0.67-1.40)$ \\
\hline$>\$ 100 \mathrm{~K}$ & 1.31 & $(0.93-1.84)$ & 1.25 & $(0.91-1.71)$ \\
\hline \multicolumn{5}{|c|}{ Age (compared to <30) } \\
\hline $30-39$ & $1.79^{\star * *}$ & $(1.38-2.32)$ & $1.92^{\star \star *}$ & $(1.51-2.44)$ \\
\hline $40-49$ & $1.71^{\star * *}$ & $(1.28-2.28)$ & $2.46^{\star * *}$ & $(1.90-3.18)$ \\
\hline 50 and over & $0.75 \dagger$ & $(0.55-1.01)$ & $5.14^{\star * *}$ & $(3.80-6.96)$ \\
\hline Nonminority & $1.58^{\star * *}$ & $(1.26-1.99)$ & $0.76^{\star *}$ & $(0.62-0.94)$ \\
\hline
\end{tabular}

${ }^{*} \mathrm{p} \leq .05,{ }^{* *} \mathrm{p} \leq .01,{ }^{* *} \mathrm{p} \leq .001, \dagger \mathrm{p} \leq .10$.

TABLE 3. Logistic Regression Analysis of Sexual Activity with Women in Last Five Years

\begin{tabular}{|c|c|c|c|c|}
\hline & \multicolumn{2}{|c|}{ Young Adults (18-29 years old) } & \multicolumn{2}{|c|}{ Older Adults ( 30 years and older) } \\
\hline & Odds & (95 percent & & (95 percent \\
\hline & Ratio & Confidence Interval) & Odds Ratio & Confidence Interval) \\
\hline Education (years) & $0.89^{\star}$ & $(0.80-0.99)$ & 0.99 & $(0.92-1.05)$ \\
\hline \multicolumn{5}{|c|}{ Income (compared to $<\$ 20 \mathrm{~K}$ ) } \\
\hline$\$ 20,001-40,000$ & $0.64 \dagger$ & $(0.38-1.08)$ & $0.69 \dagger$ & $(0.45-1.05)$ \\
\hline$\$ 40,001-60,000$ & 0.69 & $(0.37-1.27)$ & $0.48^{\star *}$ & $(0.29-0.77)$ \\
\hline$\$ 60,001-80,000$ & $0.58 \dagger$ & $(0.26-1.26)$ & $0.61 \dagger$ & $(0.37-1.03)$ \\
\hline$\$ 80,001-100,000$ & 0.24 & $(0.05-1.13)$ & $0.26^{\star * *}$ & $(0.12-0.58)$ \\
\hline$>\$ 100 \mathrm{~K}$ & 1.21 & $(0.56-2.59)$ & 0.74 & $(0.45-1.20)$ \\
\hline \multicolumn{5}{|c|}{ Age (compared to 30-39) } \\
\hline $40-49$ & & & 0.98 & $(0.71-1.36)$ \\
\hline 50 and over & & & 1.09 & $(0.74-1.60)$ \\
\hline Nonminority & 1.12 & $(0.72-1.73)$ & $0.63^{* *}$ & $(0.45-0.89)$ \\
\hline
\end{tabular}

${ }^{*} \mathrm{p} \leq .05,{ }^{* *} \mathrm{p} \leq .01,{ }^{* * *} \mathrm{p} \leq=.001, \dagger \mathrm{p} \leq .10$.

percent of men 18-29 reported bisexual experience versus 11 percent of all men over age 29), two separate regression analyses were conducted. As the analyses in Table 3 indicate, higher education is related to reduced odds of being sexually active with women among younger men (first analysis), while higher income is related to reduced odds of being sexually active with women for older men (second analysis). 
TABLE 4. Logistic Regression Analysis of Gay Culture

\begin{tabular}{|c|c|c|c|c|}
\hline & \multicolumn{2}{|c|}{ Attend Any Gay Groups } & \multicolumn{2}{|c|}{ Read National Gay Press } \\
\hline & Odds Ratio & $\begin{array}{l}\text { (95 percent } \\
\text { Confidence Interval) }\end{array}$ & Odds Ratio & $\begin{array}{l}\text { (95 percent } \\
\text { Confidence Interval) }\end{array}$ \\
\hline Education (years) & $1.05^{\star}$ & $(1.01-1.10)$ & 1.02 & $(0.98-1.06)$ \\
\hline \multicolumn{5}{|c|}{ Income (compared to $<\$ 20 \mathrm{~K}$ ) } \\
\hline$\$ 20,001-40,000$ & 1.21 & $(0.91-1.60)$ & $1.67^{\star * *}$ & $(1.27-2.19)$ \\
\hline$\$ 40,001-60,000$ & $1.48^{\star}$ & $(1.09-2.01)$ & $1.75^{\star * *}$ & $(1.31-2.33)$ \\
\hline$\$ 60,001-80,000$ & $1.67^{\star *}$ & $(1.18-2.38)$ & $2.51^{\star * *}$ & $(1.83-3.45)$ \\
\hline$\$ 80,001-100,000$ & $1.96^{\star *}$ & $(1.27-3.05)$ & $2.42^{* * *}$ & $(1.67-3.50)$ \\
\hline$>\$ 100 \mathrm{~K}$ & $1.74^{\star *}$ & $(1.23-2.46)$ & $2.24^{\star * *}$ & $(1.64-3.05)$ \\
\hline \multicolumn{5}{|c|}{ Age (compared to $<30)$} \\
\hline $30-39$ & $1.39^{*}$ & $(1.06-1.83)$ & 1.01 & $(0.81-1.27)$ \\
\hline $40-49$ & $0.75^{\star}$ & $(0.57-0.99)$ & $0.78^{\star}$ & $(0.61-0.99)$ \\
\hline 50 and over & $0.41^{\star * *}$ & $(0.30-0.55)$ & $0.46^{\star *}$ & $(0.35-0.61)$ \\
\hline Nonminority & 1.16 & $(0.92-1.47)$ & 1.14 & $(0.93-1.40)$ \\
\hline
\end{tabular}

${ }^{\star} \mathrm{p} \leq .05,{ }^{* *} \mathrm{p} \leq .01,{ }^{* *} \mathrm{p} \leq .001, \dagger \mathrm{p} \leq .10$.

TABLE 5. Logistic Regression Analysis of Living in Gay Neighborhood

\begin{tabular}{|c|c|c|}
\hline & Odds Ratio & (95 percent Confidence Interval) \\
\hline Education (years) & $1.06^{* *}$ & $(1.02-1.10)$ \\
\hline \multicolumn{3}{|c|}{ Income (compared to < $\$ 20 \mathrm{~K}$ ) } \\
\hline$\$ 20,001-40,000$ & $1.33^{\star}$ & $(1.01-1.75)$ \\
\hline$\$ 40,001-60,000$ & $1.48^{* *}$ & $(1.11-1.99)$ \\
\hline$\$ 60,001-80,000$ & $1.55^{\star *}$ & $(1.13-2.14)$ \\
\hline$\$ 80,001-100,000$ & $1.54^{\star}$ & $(1.06-2.24)$ \\
\hline$>\$ 100 \mathrm{~K}$ & $1.56^{* *}$ & $(1.14-2.14)$ \\
\hline \multicolumn{3}{|c|}{ Age (compared to <30) } \\
\hline $30-39$ & 0.99 & $(0.78-1.25)$ \\
\hline $40-49$ & $0.78 \dagger$ & $(0.61-1.01)$ \\
\hline 50 and over & $0.72^{\star}$ & $(0.54-0.96)$ \\
\hline Nonminority & $1.30^{\star}$ & $(1.05-1.60)$ \\
\hline \multicolumn{3}{|c|}{ City (compared to San Francisco) } \\
\hline New York & $0.59^{* * *}$ & $(0.47-0.73)$ \\
\hline Los Angeles & $1.64^{\star * \star}$ & $(1.33-2.03)$ \\
\hline Chicago & $2.20^{* * *}$ & $(1.70-2.85)$ \\
\hline
\end{tabular}

${ }^{*} \mathrm{p} \leq .05,{ }^{* *} \mathrm{p} \leq .01,{ }^{* * *} \mathrm{p} \leq .001, \dagger \mathrm{p} \leq .10$. 
The respondent's openness about his sexuality was statistically unrelated to measures of social class (education and income), so the results of that multivariate analysis are not shown.

\section{Gay Culture Attitudes and Participation}

Tables 4 and 5 show that social class was related, in the expected direction, to three of the measures assessing attitudes toward gay culture and to participation in the culture. Both higher education and higher income were related to increased odds of belonging to a gay group (first analysis, Table 4), and higher income was related to increased odds of reading a national gay publication (second analysis, Table 4). For both of these outcomes, the effect of income appears to be curvilinear, with the odds ratios increasing with higher income groups but decreasing toward the highest income group.

Since the density of gay neighborhoods varies by sample city, the analysis of whether the subject lives in a gay neighborhood includes sample city as a covariate. As indicated in Table 5, both higher education and higher income are related to increased likelihood of living in a gay neighborhood when adjusting for sample city, age, and minority status. Note that the effect of income on residence increases until the $\$ 60,001$ to $\$ 80,000$ category and then levels off.

The measures of affiliation with the gay community and of exclusivity by the gay community were not related to social class.

\section{Gay Intimacy and Socializing}

Social class was related to three of the measures of how the respondent met intimacy needs and socialized with other gay men. As Table 6 indicates, having a higher education

TABLE 6. Logistic Regression Analysis of Gay Socializing

\begin{tabular}{|c|c|c|c|c|}
\hline & \multicolumn{2}{|c|}{ At Private Parties } & \multicolumn{2}{|c|}{ In Public Cruising Areas } \\
\hline & Odds Ratio & $\begin{array}{l}\text { (95 percent } \\
\text { Confidence Interval) }\end{array}$ & Odds Ratio & $\begin{array}{l}\text { (95 percent } \\
\text { Confidence Interval) }\end{array}$ \\
\hline Education (years) & $1.09^{\star * *}$ & $(1.05-1.14)$ & 0.97 & $(0.93-1.01)$ \\
\hline \multicolumn{5}{|c|}{ Income (compared to $<\$ 20 \mathrm{~K})$} \\
\hline$\$ 20,001-40,000$ & $1.39^{\star}$ & $(1.06-1.82)$ & 0.99 & $(0.76-1.29)$ \\
\hline$\$ 40,001-60,000$ & $1.55^{\star \star}$ & $(1.16-2.06)$ & $0.75^{\star}$ & $(0.57-.99)$ \\
\hline$\$ 60,001-80,000$ & $1.56^{\star *}$ & $(1.14-2.14)$ & $0.75 \dagger$ & $(0.54-1.03)$ \\
\hline$\$ 80,001-100,000$ & $1.91^{\star * *}$ & $(1.32-2.76)$ & 0.80 & $(0.55-1.16)$ \\
\hline$>\$ 100 \mathrm{~K}$ & $2.36^{* * *}$ & $(1.73-3.22)$ & $0.73^{\star}$ & $(0.53-0.99)$ \\
\hline \multicolumn{5}{|c|}{ Age (compared to <30) } \\
\hline $30-39$ & $0.65^{\star * *}$ & $(0.52-0.82)$ & 0.97 & $(0.77-1.21)$ \\
\hline $40-49$ & $0.38^{\star * *}$ & $(0.30-0.49)$ & $0.73^{\star}$ & $(0.57-0.93)$ \\
\hline 50 and over & $0.31^{\star * *}$ & $(0.23-0.42)$ & $0.54^{\star * *}$ & $(0.40-0.72)$ \\
\hline Nonminority & $1.47^{\star \star *}$ & $(1.20-1.81)$ & $0.79^{\star}$ & $(0.64-0.97)$ \\
\hline
\end{tabular}

${ }^{*} \mathrm{p} \leq .05,{ }^{* *} \mathrm{p} \leq .01,{ }^{* *} \mathrm{p} \leq .001, \dagger \mathrm{p} \leq .10$. 
TABLE 7. Logistic Regression of Primary Relationship with Male

\begin{tabular}{lll}
\hline & Odds Ratio & $(95$ percent Confidence Interval) \\
\hline Education (years) & $1.05^{\star}$ & $(1.01-1.09)$ \\
Age (compared to $<30)$ & & \\
$30-39$ & $1.64^{* * *}$ & $(1.28-2.10)$ \\
$40-49$ & $1.43^{* *}$ & $(1.09-1.86)$ \\
50 and over & 1.13 & $(0.83-1.54)$ \\
Nonminority & 1.02 & $(0.82-1.26)$ \\
\hline
\end{tabular}

${ }^{*} \mathrm{p} \leq .05,{ }^{* *} \mathrm{p} \leq .01,{ }^{* * *} \mathrm{p} \leq .001$.

and a higher income increased the odds of regularly using private parties as a means of meeting and socializing with other gays (first analysis), while higher income decreased the odds of using public cruising areas for meeting and socializing with other gays.

Table 7 illustrates the relationship between social class and being involved in a primary relationship with another male. As indicated in the table, higher education is related to increased odds of being involved in such a relationship. Higher income was also related to increased odds of being involved in such a relationship; however, because of colinearity between education and income, the equation would not pass the Hosmer-Lemeshow goodness-of-fit test with both variables included in the equation. ${ }^{9}$

The measures of social class were not related to the measures of the use of bars or of sex clubs for socializing or meeting other gays.

\section{DISCUSSION}

It has frequently been stated that gays, and particularly gay males, tend to be middle class or above. We have argued, however, that this assumption may reflect a bias because of social class effects that reduce the visibility in the gay culture of working-class men who are homosexually active. We argued that this lack of visibility would be due to a variety of economic, interpersonal, and psychosocial factors that are related to social class and that would limit the likelihood that those lower in social class would describe themselves as gay or would participate in the gay community. To isolate the effects of social class from the effects attributed to racial and ethnic discrimination, we have focused on the effects of social class after controlling for minority status. Of the 14 possible effects hypothesized, 9 were statistically significant and in the direction that was hypothesized, the remaining results were not statistically significant. The results, thus, provide consistent support for an effect of social class on sexual self-expression and community involvement.

If we reverse the findings in the tables for the measures of higher social class (income or education) so as to focus on those lower in class, we find that being lower in social class is related to a decreased likelihood of describing oneself as gay, participating in gay social groups, reading the national gay press, living in a neighborhood that would be considered as a gay "ghetto," using events such as parties to socialize with other gays, and having a male primary partner. We also find that being lower in social class is related to an increased likelihood of there being a long period between initiation of sexual activity and disclosure 
that one was gay, being sexually active with women, and using a less social means (public cruising areas) for meeting other men. To summarize, the findings support the contention that working-class men are less likely to describe themselves as gay and be involved in the socially visible gay culture.

Do these results indicate support for the hypothesized economic and social processes that were proposed as the cause of less participation and visibility by the working class? Without a complete set of measures for the various economic, psychosocial, and gender processes suggested, it is not possible to test any of the suggested processes. The results, however, can be interpreted as providing potential support. The consistent effects of education and income as markers of social class on various measures of community participation suggest that economic factors that would be directly associated with education and income (e.g., higher-status occupations, disposable income) may play a part in the effects of social class. Similarly, the relationships between markers of social class and the measures of using social events versus more anonymous events for meeting partners suggest that interaction skills and cultural commonality may play a part in the effects of social class. The lower likelihood of describing oneself as gay, the longer gap between starting same-sex sexual activity and telling others that one is gay, and the higher likelihood of having women as sexual partners, all suggest that masculinity standards related to social class may affect the social lives of working-class gay men. Furthermore, the lower likelihood of being involved in a primary relationship suggests that class factors typically related to intimate relationship stability may play a part as well.

In interpreting these findings, it is important to note the limitations in both the statistical results and in the data. Focusing on the statistical results, many of the predicted relationships were significant in the multivariate results ( 9 of the 14 possible outcomes showed a relationship with social class), but some outcomes that would have been expected to be significantly related to class were not (e.g., openness as gay, perceptions of community exclusiveness). This lack of relationship is likely to be due, at least in part, to the overall homogeneity of the sample. The men in the sample are from four very urban cities with highly visible gay cultures (Chicago, Los Angeles, New York, and San Francisco), and the overall education and income levels in the sample are relatively high. Since 50 percent of the men in the sample had lived in the same city for 11 years or less, the analysis is likely to be influenced by men who chose to move to cities that are recognized as centers for gays. This self-selection process, thus, results in the elimination from the sampled population of many who, because of social class effects, do not reside in such gay centers. Thus, there may not be sufficient class variation in the sample to test some of the expected effects.

Besides these factors influencing statistical variation, it is important to stress that the UMHS was not designed to test the theoretical perspective put forth. To adequately test the complete theoretical perspective, it would be necessary to have not only additional information (e.g., family background, occupation, gender beliefs), but also to have longitudinal data. The need for longitudinal data is highlighted by the fact that we cannot assess the chronological sequence for the outcomes of this study. For example, while the analysis provided here can show that social class is related to whether the subjects label 
themselves as gay and whether they are involved in the gay community, without a historical sequencing (and more information), we cannot know if the subjects have had uncomfortable experiences with gay culture and avoid gay culture and reject the label, or if subjects have not adopted the label (for some other reason) and thus have no experience with gay culture. Considering the intricacies of the processes proposed in this study, qualitative work is needed for further development of the theory.

Despite these limitations, the diversity in the sample and the consistency of the findings provide evidence for an assertion that working-class gay men are less likely to be involved in the gay community, less likely to feel a part of the gay community, and are more likely to have long gaps in time between when they become homosexually active and when they disclose their status as gay to others. Since this research suggests the existence of important class distinctions among gays, there are important implications for both future research and gay politics.

The effects found in this research bring up two concerns about much of the research published on gays. One obvious concern brought up by these findings is the generalizability of research on gays that is based on samples of those who, in some way, identify themselves as gay. Although acquired immune deficiency syndrome (AIDS) research in recent years has incorporated concerns about MSMs and men who have sex with men and women (MSMWs), research on gays frequently uses samples of those who identify themselves as gay or who are sampled from gay resources (e.g., in gay neighborhoods or through mailing lists). Research using such samples is, thus, not likely to represent the issues and concerns of working-class gays who do not identify themselves as gay or who are not involved in the gay community. As suggested by this research, the analysis from such samples may then be biased toward the experiences of middle-class gay men. A second concern is that research, although often controlling for social class, seldom attempts to identify class differences in the experiences of gays. Both concerns reflect an implicit assumption of homogeneity among gays and, thus, may not be tapping into important class differences in the effects of sexual behavior and community on outcomes such as health (mental or physical), discriminatory practices, or legal problems.

Of greater concern, however, are the social and political implications that invisibility has for a subset of a minority group that is publicly identified through their lifestyle, not through physical characteristics. Polling in recent years has shown a steady and increasing public acceptance of gays, with analysts frequently attributing that increasing acceptance to more and more people knowing someone who is gay (Mehren 2004; Ricci and Biederman 2004). Those same polls also show that acceptance levels have increased primarily among those poll respondents who are higher in education or income (Bowman 2004). Thus, with increases in acceptance being primarily by the middle class, and if such increases are due to higher visibility by middle-class gays, it is likely that this acceptance is due to a perceived lack of difference between middle-class gays and middle-class nongays on important social dynamics. Problems are likely to arise for working-class gays, however, when acceptance is based on assumptions of middle-class similarity. As noted in the results presented here, working-class gays are less likely to exercise their social and sexual lives in the more middle-class, socially sanctioned forms of involvement in organizations, 
attending private parties, and having dyadic relationships; and are more likely to exercise their lives in a form that is not as accepted (e.g., public cruising).

Although freedom of diversity in sexual and emotional expression was key to the Stonewall-inspired Gay Liberation forces of the early '70s (Rimmerman 2002), the contemporary gay cultural and political efforts have attempted to describe gays as similar to nongays and to distance gay culture from the image of gays as publicly sexual beings (Valocchi 1999; Seidman 2001; Shugart 2003). Some of this distancing by gay institutions may simply be a middle-class discomfort with a sexuality that is inconsistent with middle-class values, although recent news articles (e.g., McNamara 2004) suggest that some of the distancing may also be an explicit political and social tactic by middle-class gays to avoid putting at risk efforts to attain the rights and privileges associated with a middleclass status. Thus, it is likely that the particular legal and social needs of working-class gays (e.g., the existence of public venues for meeting others, protection from entrapment) will not be included in efforts for political reform.

In closing, it is important to note that what is described here is very similar to the situation for racial and ethnic minorities - a tension between working for assimilation into the main stream (middle-class) culture and working for the acceptance of an alternative cultural expression. Thus, the findings presented here of less public visibility and less utilization of community resources by working-class gays may have an alternative explanation from the one proposed, which is that working-class gays (including men who have sex with men but do not identify as gay) may simply be rejecting the assimilationist efforts of middle-class gay culture. Only time will tell whether gay cultural and political movements will change to become more inclusive, whether working-class gays somehow assimilate, whether working-class gays are left behind by the majority of gay culture, or whether working-class gays become a force behind a move for a multiculturalist approach to sexual orientation issues.

\section{ACKNOWLEDGMENTS}

We would like to thank Joe Catania of the Center for AIDS Prevention Studies at the University of California San Francisco for use of the UMHS data and for his assistance with this project. The UMHS was primarily supported by NIMH Grant No. MH54320; supplementary support was provided by the National Institute on Aging and the Centers for Disease Control and Prevention's Division(s) of HIV/AIDS Prevention.

\section{NOTES}

${ }^{1}$ A note on terminology: This article addresses the experiences of men who describe themselves as gay as well as of those who are sexually active with other men but who do not describe themselves as gay. It would thus be more accurate to use the abbreviation MSM (men who have sex with men) to make this distinction. However, since the phrase MSM is not widely used, the term "gay" is used here.

${ }^{2}$ Many would argue that the broader culture's apparent increasing acceptance of gays has made this situation less likely to be true. However, this may be a class-biased acceptance, a situation that is addressed in the discussion. 
${ }^{3}$ Note that this argument assumes that labeling oneself as gay occurs at some point either relatively close in time before one's first episode of same-sex sexual behavior or after such behavior occurs. While some men do state that they started describing themselves as gay many years prior to becoming sexually involved with other males, this pattern is rare in the United States. In the data used for this study, only 6.7 percent identified themselves as gay two or more years prior to first engaging in same-sex behavior. See Dube (2000) for a discussion of behavior/identity sequencing.

${ }^{4}$ No measure was available for when respondents began to think of themselves as gay, and telling someone that one is gay is not necessarily the same as considering oneself to be gay. The process of telling someone, however, is likely to represent the beginning of the social process of selfdescription and is thus used here.

${ }^{5}$ For respondents who said that they never told anyone that they were gay, their current age was used.

${ }^{6} \mathrm{~A}$ measure of any lifetime sexual experience with women was also available. The measure of experience in the last five years was used to differentiate early sexual experimentation from factors that may be influential across the life course. An analysis of this lifetime experience variable yielded results similar to the results using the five-year experience variable.

${ }^{7}$ Organization types included professional, gym/health club, recreational, religious, political, 12 step, and charitable/social service.

${ }^{8}$ Median splits for the affiliation and exclusivity scores were also examined.

${ }^{9}$ The relationship between income and being involved in a primary relationship is not shown. Income was measured as household income, and in the upper categories of income, more than 50 percent of the respondents reported having a live-in partner. Since the predictor, high household income, is partially a function of the outcome, having a partner that shares income, the odds ratios for the upper income groups are exceptionally large and misrepresent the effects of social class on the odds of having a partner.

\section{REFERENCES}

Adler, Nancy E., Thomas Boyce, Margaret A. Chesney, Sheldon Cohen, S. Folkman, R. Kahn, and S. L. Syme. 1994. "Socioeconomic Status and Health: The Challenge of the Gradient." American Psychologist 49: 15-24.

Barrett, D. C. 2000. "Masculinity among Working Class Gay Men." Pp.176-205 in Gay Masculinities, edited by Peter Nardi. Thousand Oaks, CA: Sage.

Barrett, D., L. Pollack, and M. Tilden. 2002. Teenage Sexual Orientation, Adult Openness, and Status Attainment in Gay Males. Sociological Perspectives 45(2): 163-82.

Bowman, Karlyn H. 2004. "Attitudes about Homosexuality and Gay Marriage: AEI Studies in Public Opinion.” American Enterprise Institute. Retrieved June 18, 2004 (http://www.aei.org/ publications/pubID.14882,filter./pub_detail.asp).

Catania, J. A., D. Osmond, R. D. Stall, L. Pollack, J. P. Paul, S. Blower, D. Binson, J. A. Canchola, T. C. Mills, L. Fisher, K.-H. Choi, T. Porco, C. Turner, J. Blair, J. Henne, L. L. Bye, T. J. Coates. 2001. "The Continuing HIV Epidemic among Men Who Have Sex with Men." American Journal of Public Health 91(6): 907-914.

Chinni, Dante. 2004. "NASCAR Dads—Now You See Them, Now You Don't." Christian Science Monitor 96(62): 9.

Conger, Rand D., Ming Cui, Chalandra M. Bryant, Glen H. Elder, Jr. 2000. "Competence in Early Adult Romantic Relationships: A Developmental Perspective on Family Influences.” Journal of Personality and Social Psychology 79: 224-37. 
Connell, R. W. 1992. “A Very Straight Gay: Masculinity, Homosexual Experience, and the Dynamics of Gender." American Sociological Review 57: 735-51.

Connell, R. W. 1995. Masculinities. Berkeley: University of California Press.

Connell, R. W., M. D. Davis, G. W. Dowsett. 1993. "A Bastard of a Life: Homosexual Desire and Practice among Men in Working-Class Milieux." The Australian and New Zealand Journal of Sociology 29: 112-35.

Cunradi, Carol B., Raul Caetano, and John Schafer. 2002. "Socioeconomic Predictors of Intimate Partner Violence among White, Black, and Hispanic Couples in the United States." Journal of Family Violence 17: 377-89.

Dube, Eric M. 2000. "The Role of Sexual Behavior in the Identification Process of Gay and Bisexual Males." Journal of Sex Research 37: 123-32.

Ehrenreich, Barbara. 1995. “The Silenced Majority: Why the Average Working Person Has Disappeared from American Median and Culture." Pp. 40-2 in Gender, Race, and Class in Media, edited by Gail Dines and Jean M. Humez. Thousand Oaks, CA: Sage.

Escoffier, Jeffrey. 1998. American Homo: Community And Pervisty. Berkeley: University of California Press.

Lareau, Annette. 2002. "Invisible Inequality: Social Class and Childrearing in Black Families and White Families." American Sociological Review 67: 747-76.

Levine, Martin. 1998. Gay Macho: The Life and Death of the Homosexual Clone. New York: New York University Press.

M. C. 2004. "Among the NASCAR Dads." Nation 278(11): 18.

McNamara, Mary. 2004. "When Gay Lost Its Outre; Homosexuality Has Gone Mainstream-But with the Daggers Sheathed and Sex Unmentioned, It's One Big, Dull Party." Los Angeles Times, April 25, E1.

Mehren, Elizabeth. 2004. “Acceptance of Gays Rises among New Generation." Los Angeles Times, April 11, A1.

Mills, Thomas C., Ron Stall, Lance Pollack, Jay P. Paul, Diane Binson, Jesse Canchola, and Joseph A. Catania. 2001. "Health-Related Characteristics of Men Who Have Sex with Men: A Comparison of Those Living in 'Gay Ghettos' with Those Living Elsewhere." American Journal of Public Health 91: 980-83.

Ricci, James and Patricia Ward Biederman. 2004. "Acceptance of Gays on Rise, Polls Show." Los Angeles Times March 30, B1.

Rimmerman, Craig A. 2002. From Identity to Politics: The Lesbian and Gay Movements in the United States. Philadelphia: Temple University Press.

Seidman, Steven. 2001. "From Identity to Queer Politics: Shifts in the Social Logic of Normative Heterosexuality in Contemporary America." Social Thought \& Research 24: 1-2, 6-12.

Shugart, Helene A. 2003. "Reinventing Privilege: The New (Gay) Man in Contemporary Popular Media." Critical Studies in Media Communication 20: 67-91.

South, Scott J. 2001. “The Geographic Context of Divorce: Do Neighborhoods Matter?” Journal of Marriage \& the Family 63: 755-66.

Valocchi, Steve. 1999. “The Class-Inflected Nature of Gay Identity.” Social Problems 46: 207-24.

White, Lynn and Stacy J. Rogers. 2000. "Economic Circumstances and Family Outcomes: A Review of the 1990s." Journal of Marriage \& the Family 62: 1035-51.

Winkleby, M., S. Fortmann, and D. Barrett. 1990. "Social Class Disparities in Risk Factors for Disease: 8 Year Prevalence Patterns by Level of Education." Preventive Medicine 19: 1-12. 